\title{
BMJ Open Are communities of practice a way to support health literacy: a study protocol for a realist review
}

\author{
Sanne H Elbrink (D), Shandell L Elmer, Richard H Osborne
}

To cite: Elbrink SH, Elmer SL, Osborne RH. Are communities of practice a way to support health literacy: a study protocol for a realist review. BMJ Open 2021;11:e048352. doi:10.1136/ bmjopen-2020-048352

- Prepublication history and additional supplemental material for this paper are available online. To view these files, please visit the journal online. (http://dx.doi.org/10.1136/ bmjopen-2020-048352)

Received 22 December 2020 Accepted 09 June 2021
Check for updates

\section{(c) Author(s) (or their} employer(s)) 2021. Re-use permitted under CC BY-NC. No commercial re-use. See rights and permissions. Published by BMJ.

Centre for Global Health and Equity, Faculty of Health, Arts and Design, Swinburne University of Technology, Hawthorn, Victoria, Australia

Correspondence to Mrs Sanne H Elbrink; selbrink@swin.edu.au

\section{ABSTRACT}

Introduction Communities of practice are used for knowledge sharing and learning in health settings. However, more needs to be known to understand how they work, if they work different in different settings and what outcomes they might generate. Of particular interest is their potential role in health literacy development. Methods and analysis This realist review will be undertaken in seven stages, aiming to develop a framework to show how the various contexts of communities of practice in health settings trigger mechanisms that lead to improved health literacy outcomes. The first stage of a realist review is considered important as it clarifies the scope of the review, yet it is rarely elaborated in detail. This paper describes this first stage in detail and shows how scoping techniques can support drafting an initial framework which can guide the rest of the review. After the initial scoping review, the subsequent stages follow an iterative and recurring process (until saturation is reached) that includes searching and appraising evidence, extracting and organising results, and analysing and summarising. The review will then generate conclusions and recommendations for stakeholders seeking to use communities of practice for their health literacy challenges. Findings of the scoping review are presented in this paper as part of the methods description to show the relevance of conducting a scoping review prior to a realist review.

Ethics and dissemination Ethical review is not required for this review. Experts and stakeholders will be involved in the process after the first stage to increase the quality of the process and to ensure practical relevance and uptake. This review focuses on communities of practice and health literacy, yet findings will likely be relevant for other health settings. Findings will be disseminated through stakeholders, publications, presentations and formal and informal reports.

\section{INTRODUCTION \\ Background}

In 2020, WHO launched a list of urgent health challenges for the next decade (table 1$)^{1}$ in line with the United Nations (UN) 'decade of action' to reach the 2030 Sustainable Development Goals (SDGs). ${ }^{2}$ These health challenges are a global responsibility, which is greater than the health sector, and both

\section{Strengths and limitations of this study}

- First review which seeks to increase the understanding of communities of practice to improve health literacy.

- Exploration of a scoping review as a systematic approach of conducting the first stages of a realist review which then guides the realist review.

- Support future realist review researchers by providing a detailed description of the first stage of a realist review.

- Practical recommendations for organisations and practitioners in establishing communities of practice.

- Absence of expert and stakeholder involvement in the first stages may limit the initial theory building stage.

the WHO and UN are calling out for global action to work better together. ${ }^{2}$ Communities of practice are a way for individuals, organisations and countries to work better together, to deepen knowledge, to share best practices and to learn from each other via ongoing interaction. ${ }^{3}$ Communities of practice are common in health settings ${ }^{4}$ and contribute to improving healthcare and accelerating innovation. ${ }^{67}$

With the growing application of communities of practice in health settings, there is a need to better understand how they work, if they work differently in different contexts and under what conditions they achieve their intended outcomes. ${ }^{8}$ One of the emerging fields that underpins the above WHO challenges which might benefit from this understanding is health literacy, defined by the WHO as the 'ability of individuals and communities to undertake the tasks to access, understand, appraise, remember and apply information about health in everyday life, continuously throughout the life course'. According to the WHO, the need to increase health literacy is crucial to realise the social, economic and environmental SDGs. ${ }^{10} 11$ An in depth understanding of how communities of practice work best, will assist countries, 


\begin{tabular}{|c|c|}
\hline $\begin{array}{l}\text { Elevating health in the climate } \\
\text { debate }\end{array}$ & $\begin{array}{l}\text { Investing in the people } \\
\text { who defend our health }\end{array}$ \\
\hline $\begin{array}{l}\text { Delivering health in conflict and } \\
\text { crisis }\end{array}$ & Keeping adolescents safe \\
\hline Making healthcare fairer & Earning public trust \\
\hline Expanding access to medicines & $\begin{array}{l}\text { Harnessing new } \\
\text { technologies }\end{array}$ \\
\hline Stopping infectious diseases & $\begin{array}{l}\text { Protecting the medicines } \\
\text { that protect us }\end{array}$ \\
\hline Preparing for epidemics & Keeping healthcare clean \\
\hline $\begin{array}{l}\text { Protecting people from } \\
\text { dangerous products }\end{array}$ & \\
\hline
\end{tabular}

organisations and professionals that work on health literacy and related areas, including WHO's current network of National Health Literacy Demonstration Projects teams, ${ }^{12}$ to set up and run communities of practice.

\section{Communities of practice in health settings}

Communities of practice are 'groups of people who share a concern, a set of problems, or a passion about a topic and who deepen their knowledge and expertise in this area by interacting on an ongoing basis'. was first introduced by Lave and Wenger as a learning tool for novices to learn from experts within the contexts of workplaces, ${ }^{13} 14$ followed by a way for organisations to manage knowledge workers. ${ }^{3}$ The concept is linked to the early study of occupational communities ${ }^{15}$ and quality improvement collaboratives in healthcare, where groups of professionals work together outside their regular work teams to improve the quality of care. ${ }^{16} 17$

Communities of practice in health settings emerged in the literature around $2000^{18}$ in a variety of settings. These settings included communities of practice that support the development and implementation of local prevention plans in Italy, ${ }^{19}$ a community of practice to improve falls prevention in aged care, ${ }^{20}$ and a community of practice where regionally dispersed nutritionist exchanged knowledge about changing local practices and access to healthy food in rural Australia. ${ }^{21}$ Other examples are a community of practice of clinical professionals and traditional healers in Cameroon aiming to improve people's knowledge about tropical diseases ${ }^{22}$ or a virtual community of practice seeking to empower patients with chronic conditions. ${ }^{23}$ A recent review of virtual communities of practices for clinicians showed the importance of developing trust, privacy and technology and encourage active participation. ${ }^{24}$ A systematic review suggested that although communities of practice might be a useful tool in public health, weak evaluation studies make it unclear how to support communities of practice. ${ }^{25}$

Since communities of practice have become increasingly applied in recent years, their operationalisation and range of application has also become broader. ${ }^{26} 27$
Alongside this, research into communities of practice in health settings has moved in two general directions. One focuses on communities of practice that have individual, and often one-way learning, as their primary goal and based on the early ideas of novices learning from experts. ${ }^{13} 14$ This includes communities of practice applied in formal educational settings that are akin to study groups. ${ }^{28} 29$ Some researchers suggest that this direction mispresents the concept of communities of practice. ${ }^{30}$ The second direction investigates a more practical use of communities of practice as a systematic way or tool to manage knowledge in and outside organisations to facilitate and improve knowledge, ${ }^{3} 3132$ daily practice and outcomes in organisations and communities. ${ }^{33}$ The latter direction fits the quest for using communities of practice as a way to accelerate health literacy through improving health literacy knowledge, skills of practitioners and individuals, as well as system-level change within and between organisations. $^{12}$

Studies of communities of practice in the context of health literacy are scarce. ${ }^{34} 35$ In order to apply CoP to improve health literacy, we need focus on communities of practice that apply the key elements of health literacy that is, accessing, understanding, appraising, remembering or applying of health information. ${ }^{9}$ It is also important to distinguish between programmes seeking to improve the health literacy of individuals and those that seek to improve the health literacy responsiveness of governments and organisations to respond to the health literacy needs of individuals and communities. ${ }^{36}$ To further improve health literacy, there is a need to maintain and share the current knowledge and experiences from professionals and organisations, as well as developing and disseminating new knowledge. ${ }^{19} 10$

\section{Rationale for applying realist review}

Despite the growth of communities of practice in health settings, there is a dearth of knowledge about how they work and support health programmes. ${ }^{4527}$ Communities of practice are complex social phenomena and can be studied through a realist lens, where members and organisations are embedded in multiple social systems. ${ }^{37}$ The different experiences of members influence outcomes. Outcomes subsequently change the members' experience, and this might change the context and conditions of what made the community of practice work in the first place. Communities of practice are also complex because they follow a non-linear, sometimes erratic pattern of development, with different outcomes in different stages of establishment. ${ }^{3} 37$

Realist inquiries, in particular Pawson's realist evaluation approach as an application of the scientific realism paradigm, are well suited to the study of complex social phenomena as they explore what works, for whom, in what circumstances and under what conditions. ${ }^{37-40} \mathrm{~A}$ realist review aims to gain understanding in retrospectively of causality and uses context-mechanism-output configurations (CMO-configurations) to explain how 
underlying mechanisms within certain contexts lead to certain outcomes. ${ }^{37}$ A realist approach has the advantage of being policy-friendly and practical in indicating why some programmes, interventions or innovations work better in one context than in another context. A realist review explores rival explanations to serve as a justification for policy-makers to undertake certain actions ${ }^{37}$ and supports development of new health policies. ${ }^{41} \mathrm{~A}$ further strength of realist reviews is that they may include qualitative and quantitative research as well as grey literature, and might include interventions not reported in scholarly journals, yet that may have been widely applied in realorld contexts. ${ }^{394142}$

This study protocol describes seven stages of a realist review, with a focus on clarifying the scope of the review. ${ }^{37}$ Although researchers have emphasised the importance of being rigorous in the first stages, these first stages are usually not elaborated in great length in (protocols of) realist reviews, ${ }^{37}$ making the review less transparent and difficult to replicate. ${ }^{43} 44$ In this review, we use scoping review techniques in the first stage to clarify the scope and to set up the review with an initial framework before we start the search for evidence. ${ }^{375}$ This protocol seeks to advance realist review methodology by being explicit, systematic, rigorous and transparent in the initial establishment stage of the review.

\section{METHODS AND ANALYSIS}

The focus of this realist review is on communities of practice in health settings, and specifically explores whether they might support health literacy development. Since studies of communities of practice who explicitly focus on health literacy are scarce, ${ }^{34} 35$ we include communities of practice that focus on at least one of the elements of health literacy as defined by the WHO. ${ }^{9}$ We also apply the definition of communities of practice from Wenger t $_{\text {al. }}{ }^{3}$ Consequently, we will include communities of practice consisting of professionals working in health settings, and other professionals such as policy-makers, researchers and support staff or non-professionals, such as consumers, patients, clients or carers participate alongside health professionals. ${ }^{346}$ The initial focus is on purposefully established communities of practice. We will only include communities of practice where members join on a voluntary basis and we initially focus on communities of practice with members from different organisations. Project groups or other workplace-related groups or teams are excluded $^{3}$ where membership is required by an employer or intraorganisational communities of practice. ${ }^{47} 48$ Publications of communities of practice are excluded where the only aim is to improve individual knowledge and learning such as study groups, within having a common aim. We acknowledge that there are other groups that are akin to communities of practice, such as communities of interest, ${ }^{49}$ social networks ${ }^{50}$ multidisciplinary teams ${ }^{51}$ or knowledge communities, ${ }^{4}$ and explore publications of these groups to examine if there are mechanisms in

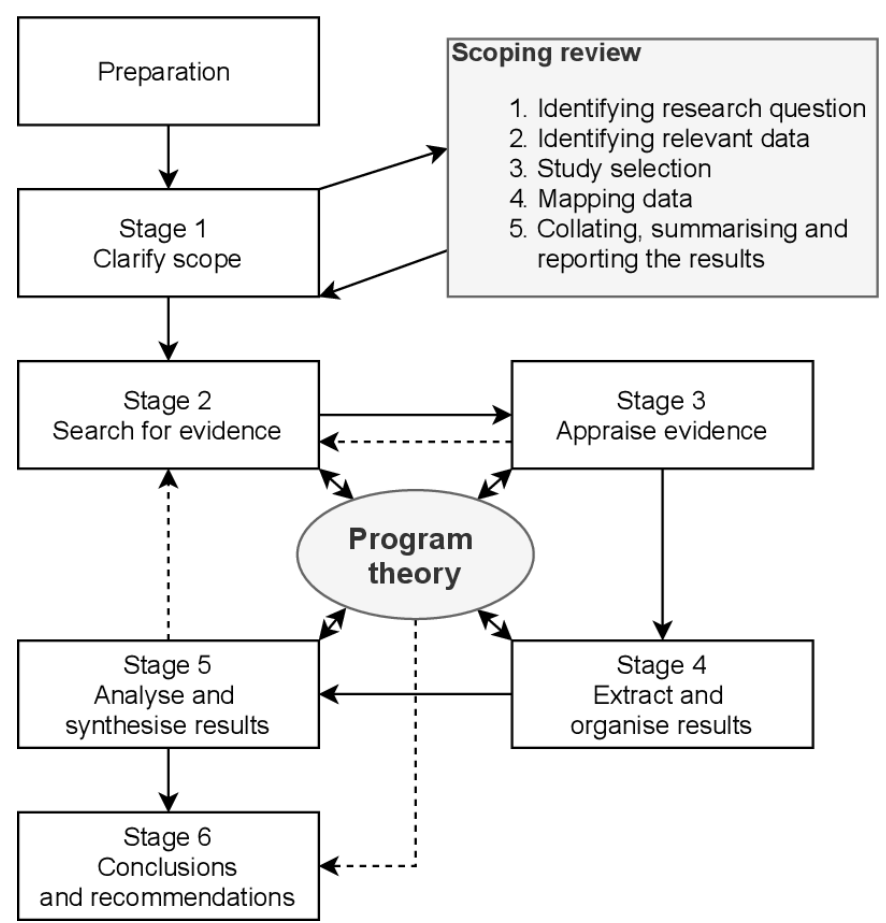

Figure 1 Overview of the realist review process integrating a scoping review. ${ }^{37414552 .}$

these groups, that can assist the understanding of related features in communities of practice.

This review follows seven stages (figure 1), based on realist reviews described by Pawson $e t a l^{37}$ and the RAMESES publication standards. ${ }^{41}$ The involvement of stakeholders to maximise end-user relevance is planned from stage 2 and onwards. ${ }^{37} 41$ The review process was modified to fit the needs of this review where we integrated the scoping frameworks of Arksey and O'Malley ${ }^{45}$ and Levac et $a l^{52}$ The process was drafted after a preparation stage with a background search about communities of practice in health settings.

\section{Patient and public involvement \\ No patients involved.}

\section{Stage 1: clarify scope}

There is little specific guidance in the literature regarding scope clarification in a realist review. ${ }^{37} 4344$ For this protocol, we specify scoping techniques to identify research gaps and to determine how to narrow the scope in relation to health literacy. A combination of two contemporary scoping frameworks with five consecutive steps are outlined; (SR1) identify the research question, (SR2) identify relevant studies, (SR3) study selection, (SR4) map the data and (SR5) collate, summarise and report results, with an option to supplement with a consultation exercise. ${ }^{45} 52$

The first step (SR1) consists of identifying a clear research question; What is known in the peer-reviewed literature about communities of practice in health settings, and how it supports clarification and specification of the scope of a realist review? We seek to set up a 
Table 2 Summary of steps 3 and 4 of the scoping review; inclusion and exclusion and data mapping

\section{Exclusion criteria}

Non-peer-reviewed or non-scholarly publications

Non-English language

Publications 2000 and onwards

Boolean search term not included in title and/or abstracts (no full text search)
Inclusion criteria

Suggestion of community of practice

Suggestion of a health setting

Suggestion of change (or innovation, intervention,

improve)

No focus on formal education

\title{
Search results \\ 1233 publications included after search and deleting duplicates from the following databases: PubMed (286), ProQuest (322), EBSCOhost (591), Cochrane (43), OVID (Embase) (78), ScienceDirect (146), Scopus (556), Web of Science (496) and Wiley Online (120). \\ 764 publications included and imported in Nvivo V.12 after scanning titles and/or abstracts.
}

Additional exclusion criteria

Not primary research

\begin{abstract}
Scan full texts results
After reading full texts, we excluded 409 publications based on not meeting the inclusion criteria and 249 publications based on the additional exclusion criteria. 106 publications were directly included for data charting and an additional eight publications were added based on scanning all reference lists.

\section{Data mapping 114 publications}

General categories: authors, year of publication, country of data collection, health setting, methodology. Structure categories: organisational structure, foundation, geographical location, type of members. Interaction categories: communication environment, communication synchronicity. Content: definition, aim of the study and the community of practice, key theories and findings.
\end{abstract}

framework for the stages of the realist review based on the current literature and to determine a specific research scope for communities of practice that contribute to health literacy. This step corresponds with the first step in both scoping frameworks, ${ }^{452}$ as well as with the first stage of a realist review where the aim is to formulate the initial research question. ${ }^{37}$

In the second (SR2) and third steps (SR3), the search strategy, inclusion and exclusion criteria were developed (table 2 and online supplemental file 1). ${ }^{45}$ The criteria were amended during the search to-based on realist principles-immediately apply new acquired insights. The lack of specific health literacy publications meant the initial scope was broad, focusing on the extent, range and nature of research activities of communities of practice in health settings that aimed to improve care. ${ }^{34} 35$ The search included peer-reviewed publications in relevant scholarly databases, supplemented with scanning reference lists. ${ }^{45}$ Inclusion of grey literature contributes to greater understanding and is recommended for both scoping and realist reviews. In this study, a scoping review is used to clarify the scope for a realist review, and we need to consider feasibility. Consequently, we will include grey literature from stage 2 , where it can support in-depth understanding of how and why communities of practice work. ${ }^{37} 45$

The selection of studies followed an iterative process to include and exclude publications initially through open coding using NVivo V.12 software to identify publications with the highest frequency of the word-combinations; 'community of practice', 'communities of practice', 'cop' or 'cops'. After coding 40 publications, saturation occurred, and a final data mapping form was developed
(SR4). The form was discussed within the project team and subsequently applied to chart 114 publications (online supplemental file 2). ${ }^{45} 52$

The results of the scoping review were collated and summarised in the final step (SR5). Subsequently an initial framework was drafted. In this last step we went beyond the steps described in scoping review framework of Arksey and O'Malley, ${ }^{45}$ by following Levac et a ${ }^{52}$ recommendations to increase relevance, by interpreting the data to make meaning of the results. We followed both approaches by developing an initial framework, ${ }^{45} 52$ and this corresponds with the end result of the first stage of the realist review. ${ }^{37}$

\section{Characteristics of the studies in the scoping review}

In the first stage, we included 114 publications. The majority of studies were qualitative (70) or mixedmethods studies with a large qualitative component (26). The publications covered studies in eighteen countries: Canada (25), UK (21), USA (20), Australia (7), Spain (6), Italy, Mexico, Nicaragua, Netherlands (each 3), Sweden (2), Brazil, Cameroon, Ecuador, France, India, Malawi, New Zealand and South Africa (each 1) and ten global studies. Since 2000, the number of studies per 5-year periods has been increasing: 2000-2005 (4), 2006-2010 (15), 2011-2015 (45) and 2016-2020 (50).

A majority of communities of practice focused on clinical (34) or public health (27) topics and consisted of groups of only healthcare professionals or healthcare professionals together with other professionals such as researchers, policy-makers or administration staff. Fourteen studies included communities of practice with consumer-members, such as patients, clients or carers 


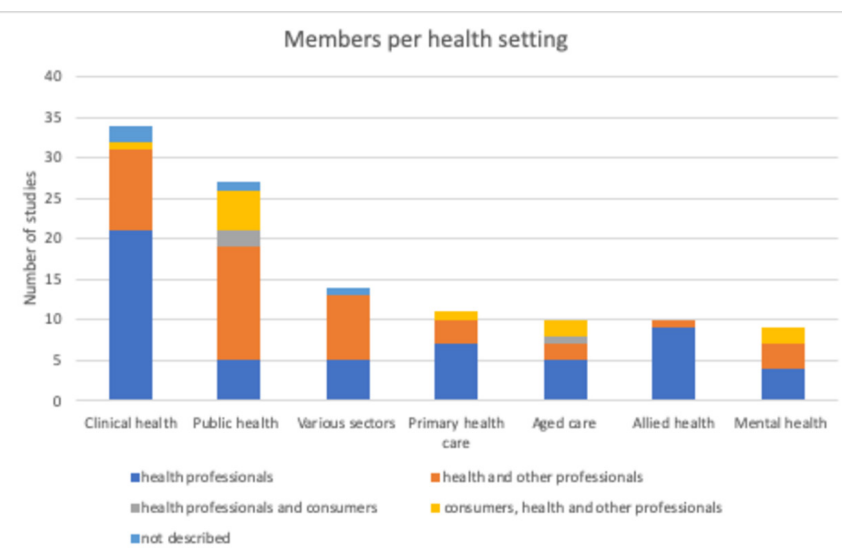

Figure 2 Overview of the members of communities of practice in different health settings and the type of members per health setting.

(figure 2). Most communities of practice were multidisciplinary $(68 \%)$.

The majority of communities of practice had been established top-down (82\%), that is, it was created, structured and organised by an initiating organisation. Thirty per cent of the publications consisted of communities of practice that were solely established for the purpose of a research project on communities of practice. Half of the communities of practice consisted of members who originated from participating organisations as voluntary delegates (54), and a third involved members who joined independently of the organisations they worked in (39). Communities of practice were operating at local, regional, national or global levels (table 3).

An approximately equal distribution of interaction mode was found across 'real life' communities of practice that interact in an offline environment without the help of digital technologies (offline, 31), communities of practice that interact with help of digital technologies (online, 35) and combined communities of practice (online and offline, 37). Most offline communities of practice solely used synchronous communication for instant interaction. Online communities of practice in general used more asynchronous-no instant interaction-communication, yet they also used synchronous or a combination of communication methods (figure 3). In the early 2000s, most online communities of practice solely focused on asynchronous methods of interaction,

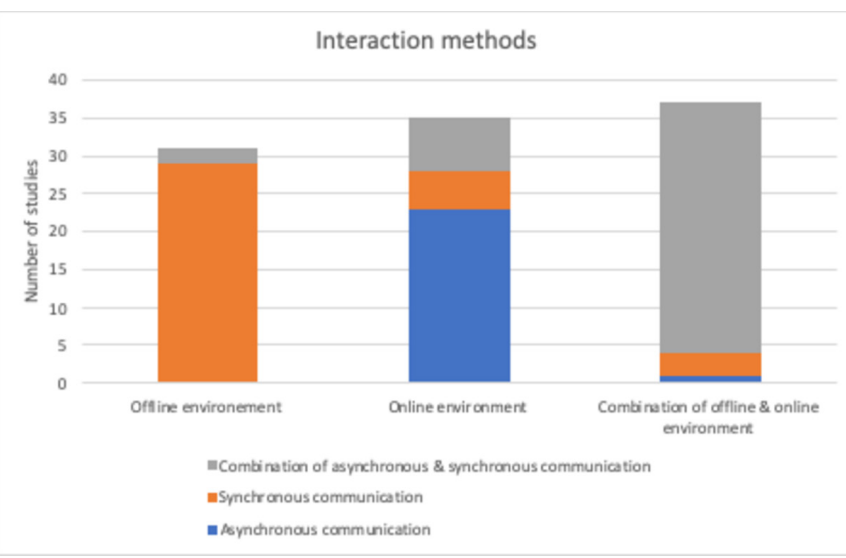

Figure 3 Overview of the environment where communities of practice interact (online/offline) and the method they use (synchronous/asynchronous).

yet the number of online communities of practice that use synchronous ways of communication has grown over the years. Recently, more communities of practice started with one 'real life' face-to-face meeting before moving to an online environment.

\section{Findings of the scoping review}

The characteristics of the identified communities of practice show that there is a high variation in communities of practice and that no two are the same. Outcomes of communities of practice can be affected by different contexts on different levels such as the individual member, the organisation(s) where the community and its members are connected to, and the context of the system or culture where the community of practice is embedded in. We also identified fixed and variable contexts. Fixed contexts tend to be static elements for example the type of members, the development stage of the community of practice ${ }^{5354}$ policy decisions and local developments. ${ }^{556}$ Variable contexts are potentially modifiable by facilitators or members during the course of a community of practice and include ways of interacting, the activities or the structure of the community of practice, the availability of facilitation, resources or time. ${ }^{535657}$

Findings of the scoping review furthermore suggest that there might be potential mechanisms within the communities of practice generating specific outcomes. Mechanisms appear at three levels: participant, organisation and

Table 3 Origin of members of the community of practice (CoP) and their scale of operation

\begin{tabular}{llllll}
\hline $\begin{array}{l}\text { Origin members } \rightarrow \\
\text { scale of CoP } \downarrow\end{array}$ & Total & External & $\begin{array}{l}\text { Intraorganisational/ } \\
\text { between organisations }\end{array}$ & $\begin{array}{l}\text { Interorganisational/within } \\
\text { an organisation }\end{array}$ & $\begin{array}{l}\text { Various } \\
\text { origins }\end{array}$ \\
\hline Local & 32 & 6 & 16 & 7 & 3 \\
Regional & 39 & 11 & 27 & 0 & 1 \\
National & 25 & 14 & 9 & 0 & 2 \\
Global & 10 & 6 & 2 & 0 & 2 \\
Unclear & 8 & 2 & 0 & 0 & 6 \\
& 114 & 39 & 54 & 7 & 14 \\
\hline
\end{tabular}




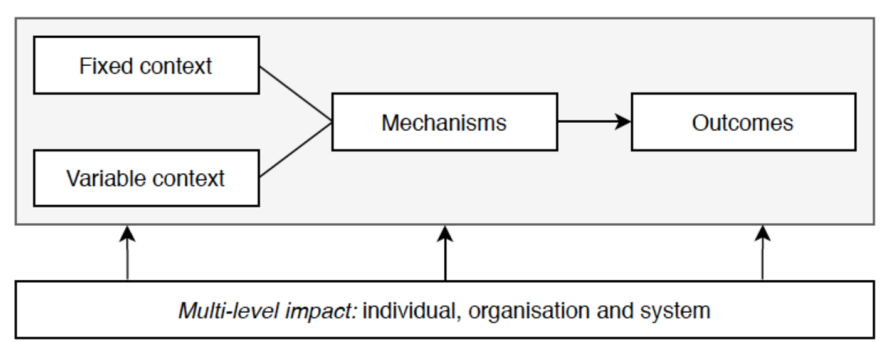

Figure 4 Initial multilevel framework of context-mechanisms outcome configurations.

system. Individual mechanisms might trigger the previous experience, skills or social capital of an individual member, ${ }^{54} 58$ empowerment, motivation or confidence building. ${ }^{56} \quad 59 \quad 60$ Potential organisational mechanisms include trust between members and their level of collaboration. ${ }^{56} 6162$ System mechanisms include openness for (policy) changes by organisations or governments or the willingness to invest in time and resources. ${ }^{563}$ The identified contexts triggers (or not triggers) include potential mechanisms which can lead to outcomes on the same three levels. These are outcomes such as knowledge or learning (individual outcomes), ${ }^{606364}$ change of practice or implementation of new ideas (organisational outcomes) s9 $^{6165}$ and policy changes ${ }^{55} 56$ or quality improvements (system outcomes).$^{58} 66$ Two studies included a health literacy community of practice as one of multiple interventions, the results indicate a role for them in sharing best practices and experiences. ${ }^{34}{ }^{35}$ Other publications indicated increased elements of health literacy, such as improved understanding of aboriginal health leading to organisational health literacy responsiveness, ${ }^{61}$ increased access and information for older people to care ${ }^{53}$ and innovation after improved understanding of children's mental health. ${ }^{60}$

We organised these findings into an initial framework (figure 4), which will guide us through the next steps of the realist review where we will study context, mechanisms and outcomes in communities of practice on different levels in relation to each other. This framework is based on communities of practice in health settings in general. We found some first indications that communities of practice might contribute to elements of health literacy via increased knowledge of its members, distributing health literacy knowledge outside the community of practice or changing daily practices and systems to become more responsive to the health literacy needs. In the next stages of the realist review, we will focus on these elements of health literacy and explore if there are contexts and mechanisms within these communities of practice that are associated with health literacy outcomes. We have formulated our research question for the next stages as follows: Which $\mathrm{CMO}$ configurations are triggered (or not triggered), why and how, in groups that act as communities of practice and lead to outcomes of improved element(s) of health literacy?

\section{Stage 2: search for relevant evidence}

The second stage of the realist review will start with a further search for relevant evidence, while taking the initial framework developed in the first stage as a starting point. We will discuss the framework and search strategy with relevant experts to increase the quality of the review process and with stakeholders in the field to increase practical relevance. The focus will be on CMO-configurations uncovered in the first stage and to examine whether they might be associated with health literacy. In the search for explanatory mechanisms, we will include alternative concepts and terms for communities of practice, research fields outside health and grey literature. ${ }^{37}$ We will specifically search for papers that provide insights in fixed and variable contexts and mechanisms that lead to outcomes on individual, organisational and systems levels and that support, reject or refine CMO-configurations. When new insights ask for a new search, we will amend and repeat the search during the following stages (figure 1). ${ }^{37}$

\section{Stage 3: appraising the quality of evidence}

Appraisal of the quality of evidence in stage 3 helps to ensure relevance and rigour and makes clear that the highest methodological standards were used and that the study is as free of bias as possible. ${ }^{37}$ Relevance tests if the study addresses the theory under test, while rigour ensures that the study makes a credible contribution. ${ }^{41}$ An appraisal tool can be used in realist review, ${ }^{6768}$ but as researchers we should be careful not to exclude studies only based on missing one quality criterium. ${ }^{374}$ We will use the mixed method appraisal tool (MMAT), for the appraisal of reviews that include qualitative, quantitative and mixed methods studies. ${ }^{68}{ }^{69}$ Publications will not be excluded based on the tool, but assist with informing the strength of the findings. We will add two questions to the MMAT for our realist setting. We first determine if a candidate paper addresses (part of) CMO-configurations (relevance) and then if the paper includes a credible explanation of the outcome found (rigour). ${ }^{67}$

\section{Stage 4: data extraction}

Data extraction follows the initial framework (figure 4) using NVivo V.12. Relevant quotes will be extracted and thematically coded with Braun and Clarke's approach ${ }^{70}$ after which they can be used in the synthesising stage (stage 5). Studies will be screened for rival or other theories not represented in the initial framework. Additional papers will be sought if needed (back to stage 2) and subsequently appraised (back to stage 3 ) and repeated until saturation is reached. ${ }^{37}$

\section{Stage 5: synthesising the evidence}

In the fifth stage, we will synthesise findings from the previous stages. The initial framework will be refined until the project team and involved experts and stakeholders agree on a final framework. ${ }^{37}$ This framework aims to show an understanding on how, why and under what conditions communities of practice can support health 
literacy. We will focus on integrating programme theories in this framework that can explain CMO-configurations. ${ }^{37}$

\section{Stage 6: drawing conclusions, framing recommendations and disseminating findings}

We will finalise our framework in the last stage and will disseminate the findings with relevant organisations in the field. ${ }^{37}$ We will follow up the review by testing the framework in upcoming empirical studies, for further refinement and continuous improvement.

\section{DISCUSSION}

This paper presents a novel study protocol as it describes the planned process for a realist review, with a best practice in how to conduct the first stage of that realist review and further elaborates the realist approach of Pawson $e t a l .{ }^{37}$ It contributes to clearer results and an insightful overview of the process, which potentially increases validity, transparency and replicability of the review. This paper provides theoretical and methodological insights by formulating an initial framework of why and how communities of practice work in different levels in health settings. The framework distinguishes fixed and variable contexts and mechanism that in different combinations lead to different outcomes. The scoping review also points to a research gap as there is little specific research on communities of practice that explicitly support health literacy. In the next stages of the realist review, the scope shifts to communities of practice that implicitly address one or more elements of health literacy. ${ }^{9}$

This protocol furthermore contributes to methodological insights. By combining different review techniques and providing a detailed written study protocol, internal validity and rigour of the study increases. Since we follow up the detailed elaboration of a scoping review with a well-informed realist review, this protocol contributes to increased transparency and replicability. ${ }^{43}$ It also strengthens external validity, which is something scoping reviews frequently lack and which makes them potentially misleading. ${ }^{71}$ We also plan to integrate the MMAT-tool in the appraisal stage of the review. ${ }^{68}$

This study protocol is potentially limited by the use of scoping review techniques to systematically structure the first stage of the realist review over other systematic review techniques, and we do not rule out the fit with other systematic review methods to support the first stage. By combining review techniques, feasibility needed to be taken in consideration, leading to exclude some scoping review components: inclusion of grey literature, inclusion of alternative concepts of communities of practice and directly engaging experts and stakeholders. This exclusion might affect clarification of the scope for the realist review, yet we will include these components directly in stage 2 and onwards in the realist review.

\section{Ethics and dissemination}

Ethical review is not required for this protocol. Dissemination of the results focus on governments and organisations working in the field of health literacy, yet the findings will also likely be relevant for other health challenges and health settings. Findings of the realist review will be disseminated through publications of the findings in peer-reviewed journals, presentations and formal and informal reports.

Twitter Sanne H Elbrink @sanneelbrink and Richard H 0sborne @richardosborne4

Contributors All authors conceptualised the research questions and SE and SLE conceptualised the analytical plan. Under supervision of SLE, SE led the development of the search strategy, selection criteria, data extraction criteria and analysis method. SE conducted the literature search. SE drafted the initial manuscript and SLE and RHO contributed to manuscript iterations. All authors read and provided feedback and approved the final manuscript. $\mathrm{RHO}$ is the guarantor.

Funding RHO was funded in part through a National Health and Medical Research Council (NHMRC) of Australia Principal Research Fellowship (APP1155125).

Competing interests None declared.

Patient consent for publication Not required.

Provenance and peer review Not commissioned; externally peer reviewed.

Supplemental material This content has been supplied by the author(s). It has not been vetted by BMJ Publishing Group Limited (BMJ) and may not have been peer-reviewed. Any opinions or recommendations discussed are solely those of the author(s) and are not endorsed by BMJ. BMJ disclaims all liability and responsibility arising from any reliance placed on the content. Where the content includes any translated material, BMJ does not warrant the accuracy and reliability of the translations (including but not limited to local regulations, clinical guidelines, terminology, drug names and drug dosages), and is not responsible for any error and/or omissions arising from translation and adaptation or otherwise.

Open access This is an open access article distributed in accordance with the Creative Commons Attribution Non Commercial (CC BY-NC 4.0) license, which permits others to distribute, remix, adapt, build upon this work non-commercially, and license their derivative works on different terms, provided the original work is properly cited, appropriate credit is given, any changes made indicated, and the use is non-commercial. See: http://creativecommons.org/licenses/by-nc/4.0/.

ORCID iD

Sanne H Elbrink http://orcid.org/0000-0001-9743-3002

\section{REFERENCES}

1 World Health Organization. Urgent health challenges for the next decade, 2020. Available: https://www.who.int/news-room/photostory/photo-story-detail/urgent-health-challenges-for-the-nextdecade

2 United Nations. Sustainable development goals - decade of action, 2020. Available: https://www.un.org/sustainabledevelopment/ decade-of-action/

3 Wenger E, McDermott R, Snyder WM. Cultivating communities of practice: a guide to managing knowledge. Boston, Mass: Harvard Business School Press, 2002.

4 Ranmuthugala G, Plumb JJ, Cunningham FC, et al. How and why are communities of practice established in the healthcare sector? A systematic review of the literature. BMC Health Serv Res 2011;11:273.

5 Barbour L, Armstrong R, Condron P. Communities of practice to improve public health outcomes: a systematic review. Journal of Knowledge Management 2018;22:326-43.

6 Shaikh U, Nettiksimmons J, Joseph JG, et al. Collaborative practice improvement for childhood obesity in rural clinics: the healthy eating active living telehealth community of practice (health COP). Am J Med Qual 2014;29:467-75.

7 Wilson AM, Delbridge R, Palermo C. Supporting dietitians to work in Aboriginal health: qualitative evaluation of a community of practice mentoring circle. Nutr Diet 2017;74:488-94.

8 Ranmuthugala G, Cunningham FC, Plumb JJ, et al. A realist evaluation of the role of communities of practice in changing healthcare practice. Implement Sci 2011;6:49. 
9 World Health Organization. WHO independent high-level Commission on NCDS report of working group 1. Geneva: World Health Organization, 2019.

10 World Health Organization. Health promotion - health literacy, 2016. Available: https://www.who.int/healthpromotion/conferences/9gchp/ health-literacy/en/

11 World Health Organization. Health literacy - health literacy and the SDGs, 2016. Available: https://www.who.int/healthpromotion/ conferences/9gchp/health-literacy-sdgs/en/

12 World Health Organization. WHO National health literacy demonstration projects (NHLDP) for the control and management of NCDS, 2017. Available: https://www.who.int/global-coordinationmechanism/activities/working-groups/GCM-NCD-Health-LiteracyDemonstration-Projects. pdf?ua $=1$

13 Lave J, Wenger E. Learning in doing: social, cognitive, and computational perspectives. situated learning: legitimate peripheral participation. Cambridge: Cambridge University Press, 1991.

14 Orr JE. Talking about machines: an ethnography of a modern job. Ithaca, New York: Cornell University Press, 1996.

15 Salaman G. Some sociological determinants of occupational communities. The Sociological Review 1971;19:53-77.

16 Fung-Kee-Fung M, Dodge J, Elit L, et al. Follow-Up after primary therapy for endometrial cancer: a systematic review. Gynecol Oncol 2006:101:520-9.

17 Endslay S, Kirkegaar M, Linares A. Working together: communities of practice in family medicine. Fam Pract Manag 2005;12:28-32.

18 Li LC, Grimshaw JM, Nielsen C, et al. Use of communities of practice in business and health care sectors: a systematic review. Implement Sci 2009;4:27.

19 Giusti A, Perra A, Lombardo F. The experience of a nationwide community of practice to set up regional prevention plans in Italy. Health Research Policy \& Systems 2017:15:1-10.

20 Francis-Coad J, Etherton-Beer C, Bulsara C, et al. Investigating the impact of a falls prevention community of practice in a residential aged-care setting: a mixed methods study protocol. J Adv Nurs 2015;71:2977-86.

21 Holden S, Ferguson M, Brimblecombe J, et al. Can a community of practice equip public health nutritionists to work with remote retail to improve the food supply? Rural Remote Health 2015;15:3464.

22 Awah PK, Boock AU, Mou F. Developing a Buruli ulcer community of practice in Bankim, Cameroon: a model for Buruli ulcer outreach in Africa. PLoS Neglected Tropical Diseases 2018;12:1-20.

23 Bermejo-Caja CJ, Koatz D, Orrego C, et al. Acceptability and feasibility of a virtual community of practice to primary care professionals regarding patient empowerment: a qualitative pilot study. BMC Health Serv Res 2019;19:403.

24 McLoughlin C, Patel KD, O'Callaghan T, et al. The use of virtual communities of practice to improve interprofessional collaboration and education: findings from an integrated review. J Interprof Care 2018;32:136-42.

25 Barbour L, Armstrong R, Condron P. Communities of practice to improve pubic health outcomes: a systematic review. Journal of Knowledge Management 2018;22:326-43.

26 Li LC, Grimshaw JM, Nielsen C, et al. Evolution of Wenger's concept of community of practice. Implement Sci 2009;4:11

27 LC L, Grimshaw JM, Nielsen C. Use of communities of practice in business and health care sectors: a systematic review. Implementation Science 2009;4:1-9.

28 Lewis R, Kelly S. GP/GPN partner* perspectives on clinical placements for student nurses in general practice: can a community of practice help to change the prevailing culture within general practice? BMC Fam Pract 2018;19:156

29 Costa R, Carvalho AA. Creating and developing communities of practice in online environments: the e-Fer platform. 9th International Conference the future of education 2019:155-9.

30 McGrath C, Liljedahl M, Palmgren PJ, et al. But how do we use it? communities of practice: a critical analysis. Med Educ 2020;54:188-95.

31 Koliba C, Gajda R. "Communities of Practice" as an Analytical Construct: Implications for Theory and Practice. International Journal of Public Administration 2009;32:97-135.

32 Brown JS, Duguid P, Learning O. And Communities-of-Practice: toward a unified view of working, learning, and innovation. Organization Science 1991;2:40-57.

33 Piat M, Briand C, Bates E, et al. Recovery communities of practice: an innovative strategy for mental health system transformation. Psychiatr Serv 2016;67:10-12.

34 Allott ML, Sofra T, O'Donnell G, et al. Building health literacy responsiveness in Melbourne's West: a systems approach. Aust Health Rev 2018;42:31-5.
35 Erikson M, Smith PD, Sparks SW. Best practices to advance health literacy in a Wisconsin adult literacy coalition. Health Literacy Research and Practice 2019;3:8-14.

36 Batterham RW, Hawkins M, Collins PA, et al. Health literacy: applying current concepts to improve health services and reduce health inequalities. Public Health 2016;132:3-12.

37 Pawson R, Greenhalgh T, Harvey G, et al. Realist review--a new method of systematic review designed for complex policy interventions. J Health Serv Res Policy 2005;10 Suppl 1:21-34.

38 Pawson $\mathrm{R}$. The science of evaluation: a realist manifesto. Thousand Oaks: Sage, 2013

39 Pawson R, Tilley N. Realist evaluation: the magenta book guidance notes. London: Cabinet Office, 2004. Available: http://www. communitymatters.com.au/RE chapter.pdf [Accessed 12 Dec 2019].

40 Pawson R, Tilley E. Realistic evaluation. Thousand Oaks: Sage, 1997.

41 Wong G, Greenhalgh T, Westhorp G, et al. RAMESES publication standards: realist syntheses. BMC Med 2013;11:21.

42 Kastner M, Estey E, Perrier L, et al. Understanding the relationship between the perceived characteristics of clinical practice guidelines and their uptake: protocol for a realist review. Implement Sci 2011;6:69.

43 Duddy $C$, Wong G. Explaining variations in test ordering in primary care: protocol for a realist review. BMJ Open 2018;8:e023117.

44 Goodman C, Dening T, Gordon AL, et al. Effective health care for older people living and dying in care homes: a realist review. BMC Health Serv Res 2016;16:269.

45 Arksey H, O'Malley L. Scoping studies: towards a methodological framework. International Journal of Social Research Methodology 2005;8:19-32.

46 Hildreth P, Kimble C, Wright P. Communities of practice in the distributed international environment. Journal of Knowledge Management 2000;4:27-38.

47 Wenger E. Communities of practice and social learning systems: the career of a concept. In: Blackmore C, ed. Social learning systems and communities of practice. Berlin: Springer, 2010: 179-98.

48 Fung-Kee-Fung M, Boushey RP, Morash R. Exploring a "community of practice" methodology as a regional platform for large-scale collaboration in cancer surgery-the Ottawa approach. Curr Oncol 2014:21:13-18.

49 Fischer G, Ostwald J. Knowledge communication in design communities. In: Bromme R, Hesse F, Spada $\mathrm{H}$, eds. Barriers and biases in Computer-Mediated knowledge communication. The Netherlands: Kluwer Academic Publishers, 2003: 1-32.

50 Norman CD, Huerta T. Knowledge transfer \& exchange through social networks: building foundations for a community of practice within tobacco control. Implement Sci 2006;1:20.

51 Gabbay J, le May A, Jefferson H. A case study of knowledge management in multi-agency consumer-informed 'communities of practice': implications for evidence-based policy development in health and social services. Health 2003;7:283-310.

52 Levac D, Colquhoun H, O'Brien KK. Scoping studies: advancing the methodology. Implement Sci 2010;5:69.

53 Bindels J, Cox K, Widdershoven G, et al. Stimulating program implementation via a community of practice: a responsive evaluation of care programs for frail older people in the Netherlands. Eval Program Plann 2014;46:115-21.

54 Ismail A, Kumar N. Empowerment on the margins: the online experiences of community health workers. Chi 2019: Proceedings of the 2019 Chi Conference on Human Factors in Computing Systems 2019.

55 Wehrens R, Bekker M, Bal R. Dutch academic collaborative centres for public health: development through time - issues, dilemmas and coping strategies. Evidence \& Policy 2012;8:149-70.

56 Alcalde-Rabanal JE, Becerril-Montekio VM, Langlois EV. Evaluation of communities of practice performance developing implementation research to enhance maternal health decision-making in Mexico and Nicaragua. Implement Sci 2018;13:41.

57 Clark M, Cornes M, Manthorpe J. Releasing the grip of managerial domination: the role of communities of practice in tackling multiple exclusion homelessness. Journal of Integrated Care 2015;23:287-301.

58 Langlois EV, Becerril Montekio V, Young T, et al. Enhancing evidence informed policymaking in complex health systems: lessons from multi-site collaborative approaches. Health Res Policy Syst 2016;14:20

59 Abos Mendizabal G, Nuño Solinís R, Zaballa González I. HOBE+, a case study: a virtual community of practice to support innovation in primary care in Basque public health service. BMC Fam Pract 2013;14:168

60 Bazyk S, Demirjian L, LaGuardia T, et al. Building capacity of occupational therapy practitioners to address the mental health 
needs of children and youth: a mixed-methods study of knowledge translation. Am J Occup Ther 2015;69:1-10.

61 Delbridge R, Wilson A, Palermo C. Measuring the impact of a community of practice in Aboriginal health. Studies in Continuing Education 2018;40:62-75.

62 Fingrut W, Beck LA, Lo D. Oncology communities of practice: insights from a qualitative analysis. Curr Oncol 2018;25:378-83.

63 Rycroft-Malone J, Burton C, Wilkinson J. Health services and delivery research. collective action for knowledge mobilisation: a realist evaluation of the collaborations for leadership in applied health research and care. Southampton (UK): NIHR Journals Library Copyright (c) Queen's Printer and Controller of HMSO 2015. This work was produced by Rycroft-Malone et al. under the terms of a commissioning contract issued by the Secretary of State for Health. This issue may be freely reproduced for the purposes of private research and study and extracts (or indeed, the full report) may be included in professional journals provided that suitable acknowledgement is made and the reproduction is not associated with any form of advertising. Applications for commercial reproduction should be addressed to: NIHR Journals Library, National Institute for Health Research, Evaluation, Trials and Studies Coordinating Centre, Alpha House, University of Southampton Science Park, Southampton SO16 7NS, UK, 2015

64 Alary Gauvreau C, Le Dorze G, Kairy D, et al. Evaluation of a community of practice for speech-language pathologists in aphasia rehabilitation: a logic analysis. BMC Health Serv Res 2019;19:530.
65 McCullough B, Small N, Prady SL. Improving smoking cessation data collection via a health visitor community of practice. Community Pract 2013;86:22-5.

66 Becerril-Montekio V, Alcalde-Rabanal J, Darney BG, et al. Using systematized tacit knowledge to prioritize implementation challenges in existing maternal health programs: implications for the post MDG era. Health Policy Plan 2016;31:1031-8.

67 Jagosh J, Pluye P, Macaulay AC, et al. Assessing the outcomes of participatory research: protocol for identifying, selecting, appraising and synthesizing the literature for realist review. Implement Sci 2011;6:24.

68 Pace R, Pluye P, Bartlett G, et al. Testing the reliability and efficiency of the pilot mixed methods appraisal tool (MMAT) for systematic mixed studies review. Int J Nurs Stud 2012; 49:47-53

69 Hong QN, Fàbregues S, Bartlett G, et al. The mixed methods appraisal tool (MMAT) version 2018 for information professionals and researchers. Education for Information 2018;34:285-91.

70 Braun V, Clark V. Thematic analysis. In: Cooper H, Camic PM, Long $\mathrm{DL}$, et al, eds. APA Handbook of research methods in psychology, vol 2: research designs: quantitative, qualitative, neuropsychological, and biological edition. Washington, DC, US: American Psychological Association, 2012: 57-71.

71 Pearson M, Coomber R. The challenge of external validity in policyrelevant systematic reviews: a case study from the field of substance misuse. Addiction 2010;105:136-45. 